\title{
Setting intelligent city tiling strategies for urban shading
} simulations

\author{
Laura Romero Rodríguez ${ }^{\mathrm{a}}$, Romain Nouvel ${ }^{\mathrm{b}}$, Eric Duminil ${ }^{\mathrm{b}}$, Ursula Eicker ${ }^{\mathrm{b}}$ \\ ${ }^{a}$ Grupo de Termotecnia. Escuela Técnica Superior de Ingenieros, Seville, Spain. \\ ${ }^{b}$ Research Center for Sustainable Energy Technologies, Stuttgart University of Applied Sciences. 70174 Stuttgart, Germany.
}

\begin{abstract}
Assessing accurately the solar potential of all building surfaces in cities, including shading and multiple reflections between buildings, is essential for urban energy modelling. However, since the number of surface interactions and radiation exchanges increase exponentially with the scale of the district, innovative computational strategies are needed, some of which will be introduced in the present work. They should hold the best compromise between result accuracy and computational efficiency, i.e. computational time and memory requirements.
\end{abstract}

In this study, different approaches that may be used for the computation of urban solar irradiance in large areas are presented. Two concrete urban case studies of different densities have been used to compare and evaluate three different methods: the Perez Sky model, the Simplified Radiosity Algorithm and a new scene tiling method implemented in our urban simulation platform SimStadt, used for feasible estimations on a large scale. To quantify the influence of shading, the new concept of Urban Shading Ratio has been introduced and used for this evaluation process. In high density urban areas, this index may reach $60 \%$ for facades and $25 \%$ for roofs. Tiles of 500 meters width and 200 meters overlap are a minimum requirement in this case to compute solar irradiance with an acceptable accuracy. In medium density areas, tiles of 300 meters width and 100 meters overlap meet perfectly the accuracy requirements. In addition, the solar potential for various solar energy thresholds as well as the monthly variation of the Urban Shading Ratio have been quantified for both case studies, distinguishing between roofs and facades of different orientations.

Keywords: radiation models; tiling strategies; solar potential; urban shading ratio.

\section{Introduction}

Urban energy modelling and simulation has seen a substantial development during the last decade, boosted by two factors: the shift of the energy transition paradigm to a city scale level and the increasingly high computational performances reached by multi-core microprocessors and Graphic Processing Units. In order to provide new digital methods for energy planning and decision support, several international research centers and private sector actors have developed urban-specific algorithms and software tools, such as CitySim (Robinson et al., 2009), UMI (Reinhart et al., 2013), or SimStadt (Nouvel et al., 2015a). These software solutions allow accurate calculations of the solar radiation on each building surface of a city. However, the scale of the case study may present a significant impediment, due to the large number of surface interactions (i.e. occlusions and reflections) and radiation exchanges which take place.

The present study addresses the issue of calculating accurately and efficiently the solar potential in such cases by using 3D city models, which are increasingly being used for complex simulations. Studies based on these models such as the one presented here are essential for energy planning, with the aim of helping to guide the process of developing future policies and being able to make informed decisions at large scales. This work has been possible through the use of innovative tiling strategies which were implemented in an urban simulation platform. In addition, the shading and reflection effects have been quantified and compared for two case studies with medium and high building densities, including analyses on roofs and facades with different orientations. 


\subsection{The importance of assessing the solar potential at an urban level}

An accurate assessment and understanding of the solar potential of cities is paramount in the context of the urban energy transition. In the conceptual phase of new urban environments, it enables urban planners to design sustainable urban layouts and forms with optimized passive (influencing the heating and cooling demand) or active (integration of photovoltaic or solar thermal systems) solar energy strategies and better quality of life (daylighting). In existing neighborhoods, a solar potential analysis is a pre-requisite to identify the roofs suitable for solar technologies and reach the renewable energy objectives essential in the framework of energy policies and regulations (Izquierdo et al., 2008). Global estimates of suitable roofs for solar integration are about $60 \%$ of the entire roof area in Europe (IEA, 2002). Understanding the solar potential helps cities achieve their objectives of energy reduction, and a shading analysis during the design phase can greatly improve PV systems performance (Zomer et al., 2016). The calculated solar potentials are often integrated in a solar atlas (also called solar cadastre), which presents solar-related information for every roof of an entire city (CUNY, 2016), region or state (LUBW, 2015).

\subsection{Existing approaches and models for solar potential evaluation}

Since solar radiation measurements on tilted surfaces are rarely available, they must be assessed based on local global horizontal solar irradiance and the city geometry (Shukla et al., 2015). The total solar radiation on a tilted surface is the sum of three basic components: direct (also called beam), reflected and diffuse radiations. Different methods and models allow to estimate each of these components and to calculate inter-reflections between objects.

- Direct radiation: it is based on the position of the sun in the sky dome (defined by the two angles azimuth and inclination) and the intensity of its direct beam, attenuated by crossing the atmosphere and the occasional clouds. The position of the sun is approximated on some models by partitioning the sky dome in a limited number of patches (Tregenza, 1987). The direct beam radiation with inter-reflections can be computed using either radiosity or ray tracing methods. Radiosity models calculate the radiation exchanges between each building surface, the ground and the different regions of the sky dome based on the law of energy conservation, while Ray tracing algorithms calculate beam propagations and reflections using different assumptions on the specularity of the reflecting surfaces.

- Diffuse radiation: it is assessed by a large number of empirical sky models, generally classified as isotropic sky models (which assume that the intensity of the diffuse sky radiation is uniform over the sky dome) or anisotropic sky models (which imply a dependence on the direction). The latter are more representative of the reality, since they take into account the effects of brightening of the horizon and the sky around the solar disk. Some of the most used diffuse radiation models are Liu and Jordan (Liu and Jordan, 1960) and Koronakis (Koronakis, 1986), both isotropic, or Hay and Davies (Hay, 1979), Reindl (Reindl et al., 1990) and Perez model (Perez et al., 1990), which are anisotropic. Diffuse reflections between the different surfaces of urban objects are calculated based on high-performance algorithms, sometimes coded in the graphic card. They mostly consider an average facade reflectivity. Since the solar radiation decreases after each reflection, some of these algorithms consider a limited number of multireflections. The two main computing approaches are again ray tracing and radiosity models.

Many of these methods have been intensively reviewed, evaluated and compared during the last years (Behar et al., 2015; Despotovic et al., 2015, 2016; El Mghouchi et al., 2016; Ineichen, 2016; Shukla et al., 2015). There are many software tools in which the different radiation estimation models are implemented, such as "Radiance", which is based on backward Ray tracing algorithms (light rays are traced in the opposite direction to the one they typically follow). However, the drawback of pure ray-tracing methods is their computational complexity and that they are time consuming. Simplifications of the sky dome are done for example with the Tregenza model (Tregenza, 1987) for the hemispherical sky radiance distribution.

Apart from the assessment of solar radiation, for the calculation of the solar potential of buildings and regions a set of input data is required. Many different approaches and models have been followed: from 
simple estimations (based on building typologies and statistics) to more complex approaches based on 3D city modelling and GIS-models. Nevertheless, the scale and level of detail required in each case have conditioned the methodologies to be used, as shown by (Freitas et al., 2015). For very precise calculations, 3D modelling is the most appropriate option, but processing every single building requires considerable computational efforts in large areas, making it unfeasible in some cases. The present study aims to shed some light in this direction by introducing tiling strategies which could contribute to studying larger areas in an accurate way.

\subsection{Solar access, shading and urban morphologies}

In dense urban environments, solar availability and urban daylight may become a scarce commodity, as a result of the complex and dynamic shading effects on the building envelope (Lobaccaro and Frontini, 2014). Several studies and software have approximated shadings through a static reduction coefficient applied to the total roof area, sometimes distinguishing between surrounding buildings and vegetation (Kurdgelashvili et al., 2016; Schallenberg-Rodríguez, 2013). However, this static average method is limited, leading to considerable differences between real and estimated solar potential (SchallenbergRodríguez, 2013). More accurate solutions based on Geographic Information System (GIS) technologies have been developed in order to consider more realistically the urban geometry and individual obstructions: the photographic approach (Cellura et al., 2011), Hillshade analysis (Hong et al., 2017), use of Digital Surface Models (Redweik et al., 2013), human inspection of satellite digital imageries (Izquierdo et al., 2008), etc. The drawback of these processes is the long computational time required for the pertinent calculations. A hint of such an issue can be seen in (Kolbe et al., 2015). In addition, errors may be found in the 3D city models, influencing the estimations. A comprehensible study on the propagation of errors in 3D city models can be seen in (Biljecki et al., 2015).

In the recent years, the international research community have emphasized and analyzed deeply the influence of the urban morphology (i.e. geometry, layout, density or built form typologies) on the solar access, shading and reflections (A.l. Martins et al., 2014; Han et al., 2015; Košir et al., 2014; Lee et al., 2016; Li et al., 2015; Sarralde et al., 2015; Takebayashi et al., 2015; Vermeulen et al., 2015; Yang and Li, 2015). Based on generic urban morphologies, Lee et al. (2016) studied the influence of Floor Aspect Ratio (FAR) on PV potential and solar irradiation on facades: a higher FAR leads to lower solar access with a very high correlation. The urban albedo, defined as the fraction of incident solar radiation that is reflected from the urban surfaces, also depends on urban morphology (Bernabé et al., 2015).

Although most methods focus on the solar potential of roofs, omitting vertical walls, some methodologies have been recently developed for both roofs and facades (Catita et al., 2014; Fath et al., 2015; Karteris et al., 2014; Takebayashi et al., 2015). Even though the irradiance reaching facades is on average lower than that of the roofs, due to the large areas concerned their total solar energy potential may be very significant (Redweik et al., 2013; Jaugsch and Lowner, 2016). Rooftop systems will have higher energy output during the summer months, while vertical facades will instead have peaks in spring and autumn (Good et al., 2014). During winter, facades could even double the solar potential, due to the more favorable inclinations (Brito et al., 2017). As it will be explained in following sections, the present work will also assess the solar potential of facades.

\subsection{Aims and objectives of this study}

The main objective of this study is to find out the most suitable computational methods, showing the best compromise between accurate shading calculation and reasonable computational complexity and requirements for large scale potential analyses on building roofs and facades. For this purpose, the urban simulation platform SimStadt (SimStadt, 2016) developed at the University of Applied Sciences Stuttgart has been used, which integrates several sky and radiation models as well as the new tiling strategies introduced in the present work, detailed in Section 2. These algorithms and methods have been applied and evaluated on two areas of the case studies presented in Section 3: Manhattan (New York, USA) and Ludwigsburg (Germany), representative of two different urban morphologies and densities.

Another contribution of the present study is that the shading and reflection effects of different models and approaches have been innovatively quantified and compared by introducing the new concept of "Urban 
Shading Ratio" (USR). It corresponds to the ratio of the yearly solar radiation on a building surface calculated by considering the shading and reflections caused by the surrounding urban objects, over the yearly solar radiation on the same building surface calculated by considering this building surface isolated on an infinite plane ground (unobstructed reference scenario). Since this study does not consider the effect of vegetation and landscape reliefs, the mentioned urban objects consist only of the surrounding buildings. Based on these USR evaluations, two best tiling strategies have been identified in Section 4 and used in Section 5 for deeper analyses of solar potential and shading quantification for the roofs and different facade orientations of the case studies. Finally, we summarize in the last section the findings of this study and propose further developments which could improve the efficiency of the proposed method.

\section{Solar radiation calculation approaches for urban energy analysis}

The urban energy simulation platform SimStadt (Nouvel et al., 2015a) used for this study allows to realize diverse urban energy analyses for districts, cities and whole regions, based on the open 3D city data model CityGML (Gröger et al., 2012). These 3D city models can be generated with LiDAR, stereo aerial photos or a digital cadaster, and may be enhanced with semantic data for buildings and facades (Eicker et al., 2014). A main asset is its object specification in five levels of detail (LOD), enabling the model to adapt to the local building information availability and resolution (Eicker et al., 2014). It is based on the German-norm DIN V 18599, and has already been evaluated with success against actual measurements in several districts (Nouvel et al., 2017). Many cities and regions have already been modeled with the CityGML format, such as the complete building stock of Germany (Nouvel et al., 2015b).

SimStadt has a modular and extensible workflow-driven structure allowing to run diverse urban energy analyses such as PV potential calculations (Romero Rodríguez et al., 2017). The platform uses different solar radiation models that the user can select depending on the applications and its requirements. This study is based on different radiation models and approaches implemented in SimStadt and compatible with urban scale applications: the Perez sky model, the Simplified Radiosity Algorithm (based on Perez sky model), and the newly introduced adaptation of the latter by using automatic tiling strategies. Naturally, there are also many other radiation models which do or do not consider obstructions and reflections, which are more or less appropriate for solar potential studies (Despotovic et al., 2015).

\subsection{Perez sky model}

The Perez all-weather sky model (Perez et al., 1990) predicts hourly (or higher frequency) global, direct and diffuse irradiance on tilted surfaces of arbitrary orientations, based on global, direct or diffuse irradiance measured on horizontal surfaces. This model relies on a set of parameters to be locally calibrated based on experimental observations. When these parameters are correctly chosen, its accuracy to assess diffuse irradiance has been proven to be high (Gueymard and Ruiz-Arias, 2016) compared with other reference sky models like Klucher (Klucher, 1979) or Hay (Hay, 1979), which is also implemented in SimStadt. When using the Perez model, there is no consideration of surrounding objects (neither occlusion nor reflections) and each building is simulated as if it were isolated. This model offers a good compromise between accuracy and simplicity but should only be used for very low urban density cities or districts.

\subsection{Simplified Radiosity Algorithm based on Perez sky model}

SimStadt also uses the Simplified Radiosity Algorithm (SRA) developed by Robinson and Stone (2005), which combines the Perez Sky model with a Radiosity computer graphics algorithm. The radiant external environment can be described by two hemispheres over and below the horizontal plan and is discretized into a certain number of finite elements (so-called patches) of known solid angles. Then, the equations modelling the radiant exchanges between each surface that reflects light diffusely and its associated occluded patches are solved, resulting in a Simplified Radiosity Algorithm. This solar radiation model accounts for the effects of obstructions in reducing direct and anisotropic diffuse radiation and contributing reflected radiation (A.l. Martins et al., 2014). It gives results in excellent agreement with the reference ray tracing program Radiance, in particular in dense districts where obstructions and shadings influence considerably the incoming solar radiations. 
Although results are five orders of magnitude quicker to produce than with a ray tracing program like Radiance, it still requires a lot of memory and computational time for urban scale studies. Indeed, the nature of the Radiosity algorithm, which computes radiation exchanges between pairs of polygons, leads to a computational time approximately proportional to the square of the number of building polygons. Over a critical district size (generally one thousand buildings), the software platform would likely crash or slow down because of memory management issues. This obviously depends on the characteristics of the computer which performs the simulations.

\subsection{Perez model with Simplified Radiosity Algorithm and automatic tiling}

For the present study, a new automatic tiling algorithm has been implemented in the SimStadt platform to overcome the memory and computing time limitations of the SRA algorithm for large districts or cities. This batch computing method divides the studied area in a number of square tiles and runs the Radiosity algorithm separately on each of them. The user may define the length of each square tile size, as well as the overlap length (see Figure 1). This method reduces the penalization of buildings situated on the borders of the tiles in comparison with the central ones, in terms of occlusion considerations and therefore calculation accuracy. On overlapping areas, the same building surface is part of several tiles, so several solar radiations are calculated for it. Only the lowest calculated radiation, which is assumed to better take into account the surrounding occlusions, will be retained.

Besides reducing the required computational memory and time, this process is highly parallelizable, which may reduce even more the computational time by using a cloud computing approach. As previously said, the computational time $T$ of the SRA is approximately proportional to the number of solved radiation exchange equations, i.e. the square of the surface polygons number. Considering that buildings are uniformly distributed in a studied area with $\mathrm{N}$ surface polygons and $\mathrm{P}$ tiles without overlap, the computational time $T_{N, P}$. with a tiling strategy will tend to be $\mathrm{P}$ times quicker than without tiling (Eq. 2), not considering the time saving linked to memory handling.

$$
\begin{gathered}
T_{N} \propto \mathrm{N}^{2} \\
T_{N, P} \propto \sum_{p=1}^{P} \mathrm{~N}_{P}^{2} \propto P *(N / P)^{2} \propto 1 / P * T_{N} \text { without parallel computing } \\
T_{N, P} \propto \mathrm{N}_{P}^{2} \propto(N / P)^{2} \propto 1 / P^{2} * T_{N} \quad \text { potentially with parallel computing }
\end{gathered}
$$

where $N$ is the total number of building surface polygons, $N_{P}$. is the number of surface polygons per tile $P, T_{N}$ is the computational time without tiling the studied district and $T_{N, P}$ is the computational time after tiling the studied district in P tiles. The consideration of tile overlaps would increase the computational time, while the parallelization of this process would decrease it (Eq. 3). The memory requirement is linked to the biggest number of surface polygons for a tile.

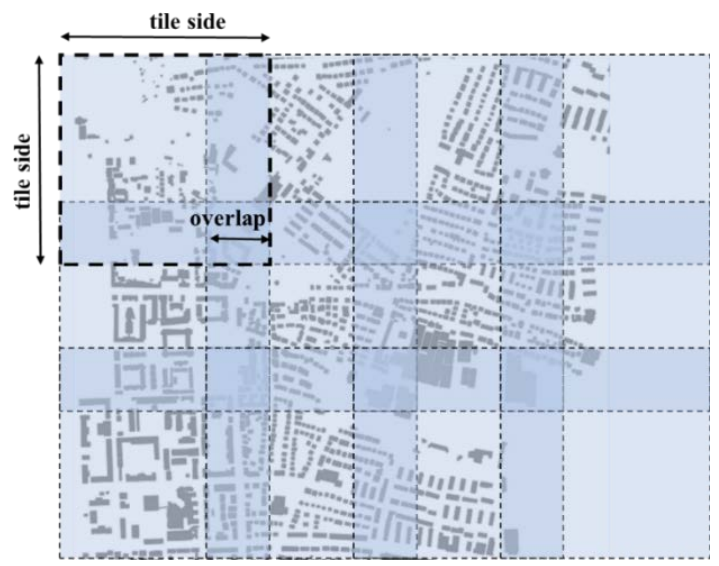


Two case studies of different densities have been selected in this work in order to analyze the impact of urban morphology on different Urban Shading Ratios.

\subsection{Medium density urban area: Ludwigsburg city center, Germany}

The City of Ludwigsburg, located at a latitude of $48^{\circ} 53^{\prime}$ in the region of Baden-Württemberg Germany, is a medium density area typical of German "middle cities". It has a total population of about 92,000 inhabitants on a territory of $43 \mathrm{~km}^{2}$. For this study, a restricted area of $2.14 \mathrm{~km}^{2}$ in the baroque city center has been selected, making a total of approximately 2200 buildings. Figure 2 shows no particular street layout, except an axis North-South splitting the city in two parts. The majority of its buildings are 20 meters high multi-family houses. The 3D city model used for this study is a CityGML Level of Detail 2 that models the buildings with their envelope and generalized roof structure, pitched or flat. The City of Ludwigsburg kindly provided this model.

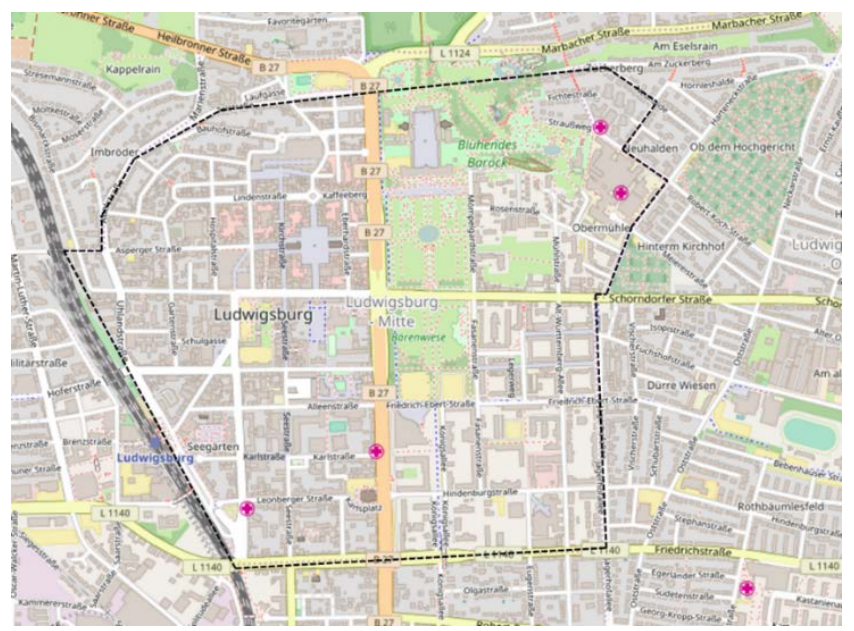

Figure 2: Area of the case study Ludwigsburg (source: openstreetmap.org).

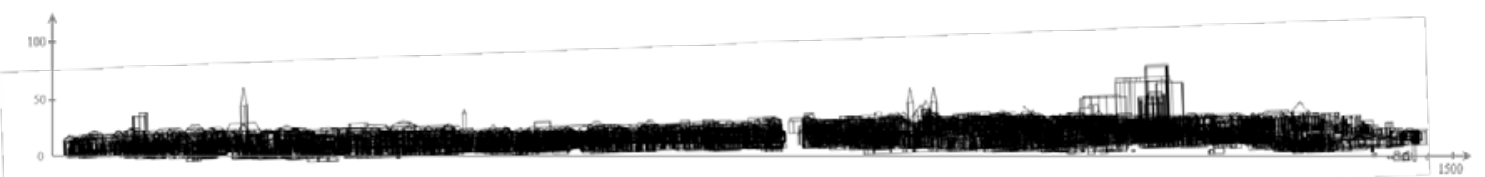

Figure 3: Representation of the case study Ludwigsburg with dimensions in meters - East view.

\subsection{High density urban area: Manhattan - New York, USA}

A part of Manhattan has been selected to represent high-density urban areas. Its urban morphology has indeed inspired many financial districts in the world. Located at a latitude of $40^{\circ} 42^{\prime}$ on a terrain with almost no relief, Manhattan is delimited by the Hudson and East rivers. For this study, an area of $8.4 \mathrm{~km}^{2}$. extending from East/West $31^{\text {st }}$ street up to Central Park has been chosen. This study area includes many emblematic locations such as the Empire State Building, $5^{\text {th }}$ avenue, Times Square, the New York Public Library or the United Nations headquarters. Figure 4 and the wired representation in Figure 5 illustrate the regular perpendicular street layout of Manhattan. The almost 6,000 buildings of this case study are mostly high-rise buildings, often reaching 100 to 300 meters' height. The 3D city model used for this study is a CityGML Level of Detail 1, modelling buildings as extrusion of their ground surface. Since most of buildings in Manhattan have flat roofs (with some exceptions such as buildings that are narrower at the top), this representation is however realistic and reliable for our study. This model has been generated by the T.U. Munich based on datasets provided in the NYC Open Data Portal (Kolbe et al., 2015). 


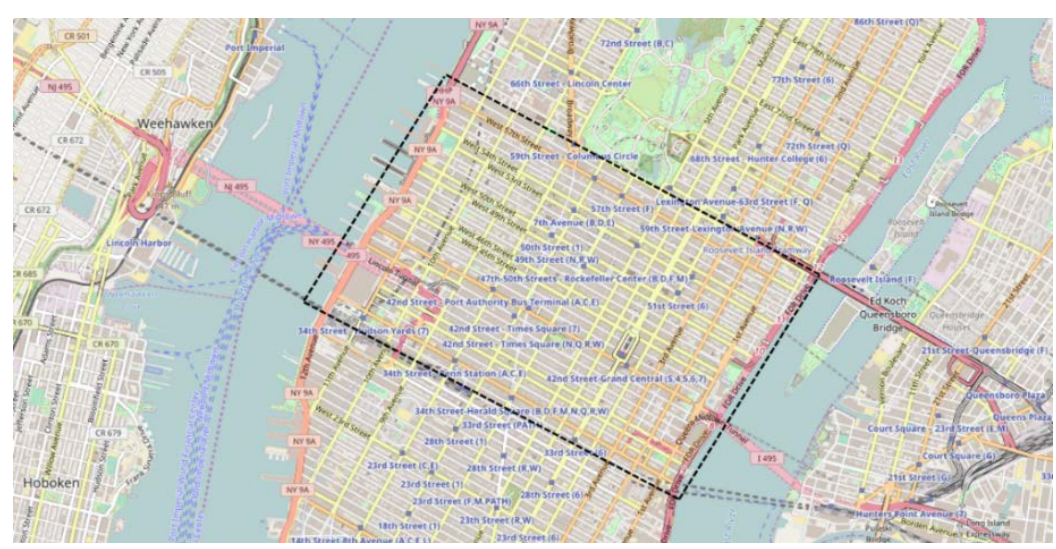

Figure 4: Area of the case study Manhattan (source: openstreetmap.org).

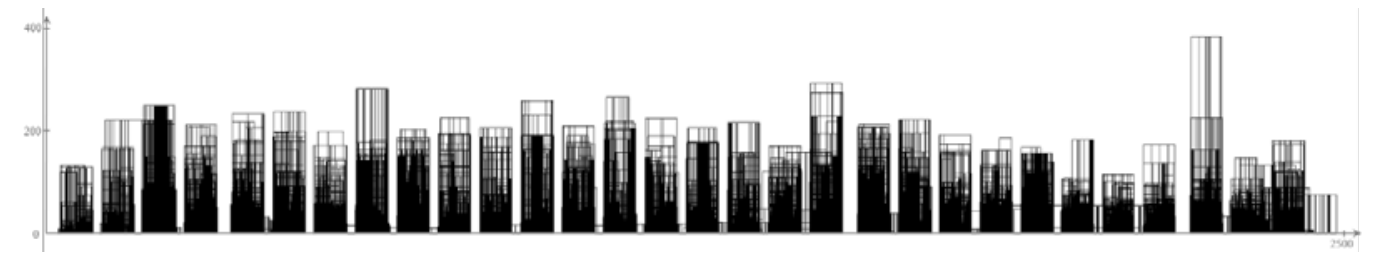

Figure 5: Representation of the case study Manhattan - North-West view.

\subsection{Key figure comparison}

In Table $1 \mathrm{a}$ comparison of the key geometric figures of both case studies can be seen. The total gross floor area considers all the horizontal areas of the spaces within all buildings, including intermediate floors. The site coverage is the quotient between the total built and ground areas (both horizontal), while the floor area ratio is the quotient between the total gross floor and ground areas. The building compactness is defined as the ratio of building surface to volume and the facade density is the ratio of building facade areas to the sum of all canopy surface areas.

\begin{tabular}{|c|c|c|}
\hline & Ludwigsburg & Manhattan \\
\hline Total ground area $\left[\mathrm{km}^{2}\right]$ & 2.14 & 8.40 \\
\hline Number of buildings & 2217 & 5882 \\
\hline Total Built Area $\left[\mathrm{km}^{2}\right]$ & 0.55 & 3.68 \\
\hline Total Gross Floor Area $\left[\mathrm{km}^{2}\right]$ & 1.99 & 80.27 \\
\hline Site coverage [-] & 0.26 & 0.44 \\
\hline Floor Area Ratio [-] & 0.93 & 9.56 \\
\hline Average building height [m] & 11.3 & 32.8 \\
\hline Average building compactness $\left[\mathrm{m}^{-1}\right]$ & 0.51 & 0.33 \\
\hline Facade density [-] & $38 \%$ & $71 \%$ \\
\hline
\end{tabular}

Table 1: Summary of features of the two case studies.

Putting aside the differences of ground areas which do not play a role in our urban shading study, these two case studies have obviously very different urban morphologies. Manhattan's Floor Area Ratio (FAR) is ten times bigger than Ludwigsburg's FAR, while the building average height is three times higher. Manhattan's buildings are also more compact. The site coverage is higher in the case of Manhattan with less solar penetration in particular at low solar elevation angles. Finally, the facade density of Manhattan is twice as big as in Ludwigsburg. Located on two different continents and slightly different latitudes, the two case studies receive also different solar radiation levels during the year as shown in Figure 6. Solar irradiances in Manhattan and Ludwigsburg remain however comparable. The solar reflectivity has been fixed to 0.2 for all facades and roofs of both case studies. The floor albedo has been set to 0.2 . 

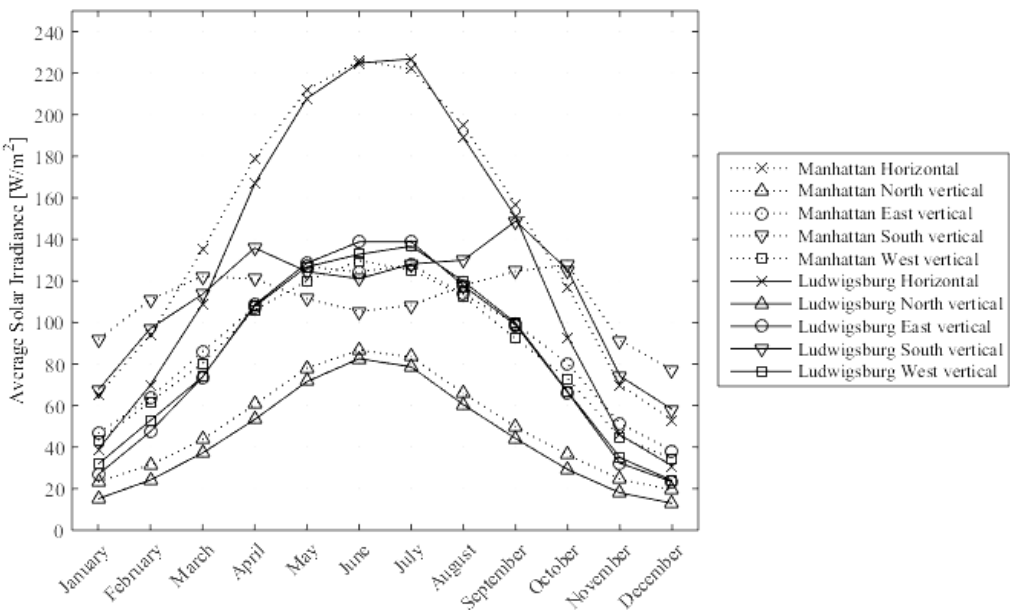

Figure 6: Average monthly irradiance for different surface orientations in Manhattan and Ludwigsburg obtained by SimStadt with the used weather files.

\section{Identifying the best tiling strategy for middle and high-density urban areas}

In this section, our study focuses on the Urban Shading Ratio, which means the relative difference between irradiances with and without consideration of the urban surroundings, rather than on absolute irradiances. Urban shading is both influenced by the local climate and the city morphology. Although both case studies have been selected mainly because of their different morphologies, their different sun positions and cloudiness may harden the interpretations of their quantitative comparison. However, we believe this study serves the understanding of the role of city morphologies in the design of the best tiling strategy.

\subsection{Issues and tiling candidates}

The Perez sky model used without the radiosity model (see Section 2.1) generates quickly the solar radiations on all building surfaces of both case studies, but the results are not accurate especially in dense urban areas since obstructions and reflections are not considered. On the other hand, the simplified Radiosity Algorithm based on the Perez sky model (see Section 2.2) applied to these two case studies is computationally heavy and crashes the software when applied to too many buildings. Radiative exchange needs to be calculated between 75880 boundary surfaces for Manhattan and 40500 for Ludwigsburg.

A compromise consists in tiling the case studies in manageable sub-areas in order to simulate the interactions only between the boundary surfaces of nearby buildings. As detailed in Section 2.3, this tiling process has been automated in the simulation platform SimStadt, with square tiles whose size and overlap parameters are user-configurable. The higher the tile size and overlap parameters, the more building interactions (e.g. obstructions and reflections) are taken into account and the more accurate the calculated solar radiations are. However, this leads to an increase of computational time and memory requirements. Therefore, finding the best tiling strategy consists in selecting the best pair \{tile size, overlap $\}$ to reach the best compromise accuracy / computational efficacy (time and memory storage). As shown later, this best tiling strategy depends on the urban morphology of the studied area.

In this section, 23 tiling strategies which combine different tile sizes (50 to 500 meters) and overlaps (0 to 200 meters) have been tested for both case studies. They are summarized in Table 2. These tiling strategies generate different numbers of tiles and considered radiation exchanges between the building surfaces (see Figure 7), which as detailed in Section 2.3 potentially corresponds to the square of the computed building surfaces number summed in all the tiles. This has a significant impact on the computational time and memory capacity requirement.

\begin{tabular}{|c|c|c|c|c|c|c|c|c|c|c|c|c|c|c|c|c|c|c|c|c|c|c|c|}
\hline $\begin{array}{c}\text { TILE SIZE } \\
(\mathrm{m})\end{array}$ & 50 & 50 & 100 & 100 & 100 & 200 & 200 & 200 & 200 & 300 & 300 & 300 & 300 & 400 & 400 & 400 & 400 & 400 & 500 & 500 & 500 & 500 & 500 \\
\hline $\begin{array}{c}\text { OVERLAP } \\
(\mathrm{m})\end{array}$ & 0 & 20 & 0 & 20 & 50 & 0 & 20 & 50 & 100 & 0 & 20 & 50 & 100 & 0 & 20 & 50 & 100 & 200 & 0 & 20 & 50 & 100 & 200 \\
\hline
\end{tabular}



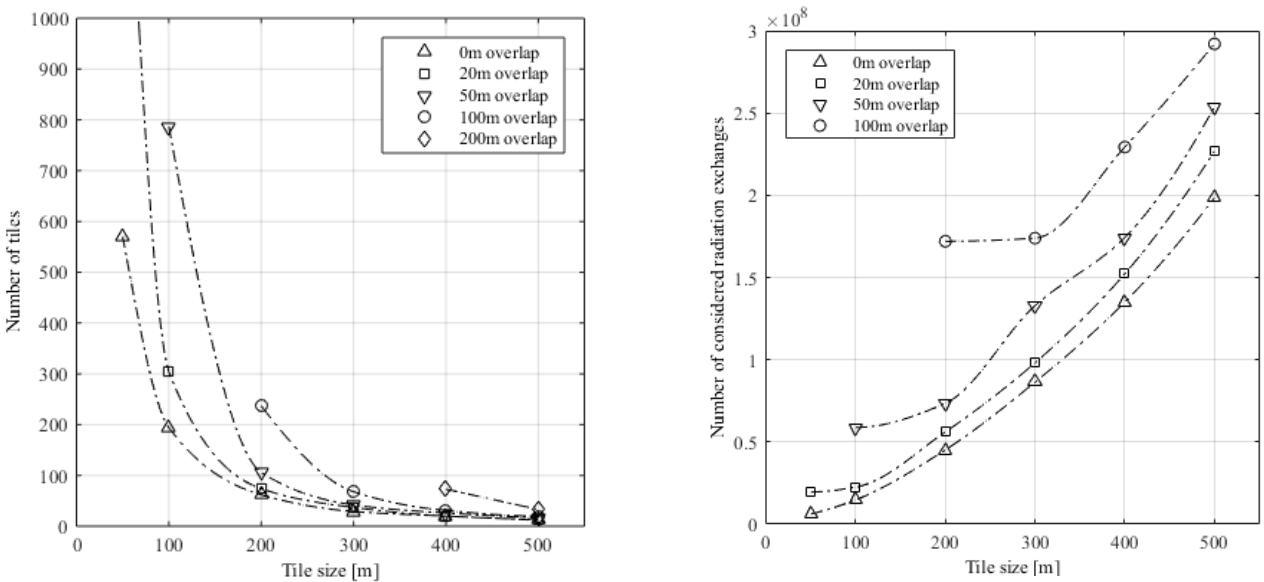

Figure 7: Number of tiles (left) and square of the computed building surfaces (right) in the Ludwigsburg case study.

In the case study Ludwigsburg, the number of tiles of the different tiling strategies varies between 1578 for $\{$ size $=50 \mathrm{~m}$, overlap $=20 \mathrm{~m}\}$ and 12 for $\{$ size $=500 \mathrm{~m}$, overlap $=0 \mathrm{~m}\}$, allowing diverse parallel computing possibilities. The average number of buildings in $50 \mathrm{~m}$ tiles is 4 , whereas $500 \mathrm{~m}$-side tiles contain 172 buildings on average. However, the number of buildings is very heterogeneous in the different tiles, varying between 1 and 570 in the different 500m tiles of Ludwigsburg for instance. Moreover, the number of considered radiation exchanges between surfaces increases with the tile size and the overlap. The combination $\{$ size $=500 \mathrm{~m}$, overlap $=200 \mathrm{~m}\}$, not represented on this graph since it goes beyond the scale limit (reaching 5.3E8), simulates potentially 85 times more radiation exchanges than the combination $\{$ size $=50 \mathrm{~m}$, overlap $=0 \mathrm{~m}\}$.

In Figure 8, the computational times of the simulations related to the different tiling strategies and case studies have been plotted in function of the tile size and overlap. The simulations have been run in a Linux server based on Intel(R) Core(TM) i5-4570 CPU @ 3.20GHz, with 4 GB RAM and 4 CPU (running in parallel) dedicated to the program SimStadt. When looking at Figure 8, it becomes apparent that the behavior of the computational time is more regular for Manhattan than for Ludwigsburg, since the
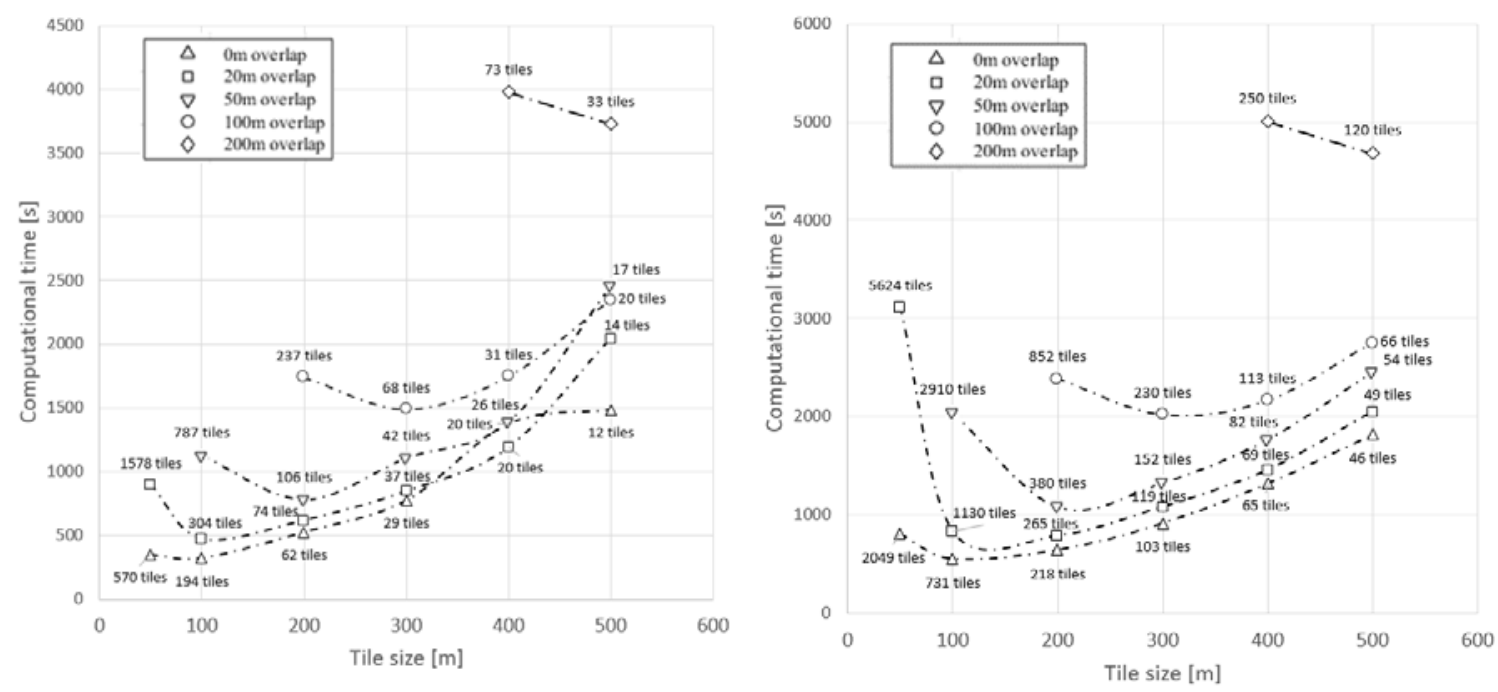

Figure 8: Computational time versus tile size for the considered strategies in Ludwigsburg (left) and Manhattan (right). The labels show also the number of tiles in each case. 
The Urban Shading Ratio (USR) of each tiling strategy is calculated as the quotient of the yearly solar radiations on all building surfaces computed using the studied tiling strategy, over the radiations computed with the reference tiling strategy $\{$ size $=0$, overlap $=0\}$ (see Eq.4). The latter corresponds to a Perez sky model without SRA (i.e. unobstructed scenario with the maximum solar potential). In this section, only the solar radiation on building roof surfaces is considered, which is generally used for photovoltaic or solar thermal potential studies.

$$
\operatorname{USR}(\text { tiling } X)=\frac{\sum \text { radiations }(\text { tiling } X)}{\sum \text { radiations }(\text { tiling }\{0,0\})}
$$

The 3D surfaces of Figure 9 represent the average USR of all building roofs weighted by their area as a function of the two tiling strategy parameters \{size; overlap\}. This figure distinguishes the annual, winter and summer USR for both case studies, calculated respectively over the 12 months of the year, for the month of January, and June. The higher these parameters are, the more complete the consideration of the solar surface inter-obstructions and reflections is and therefore the more accurate the calculation. On the other side, smaller tile sizes fail to consider numerous surface interactions, and are therefore less accurate to evaluate the urban shading impact. To be noted: increasing the Level of Detail of the 3D city models would ensure a higher accuracy, leading to an increase of both the number of building surfaces and the time needed for the pertinent calculations.

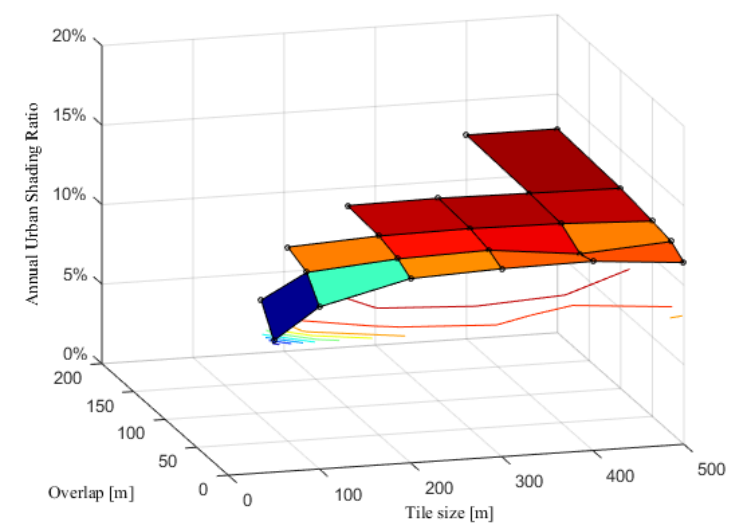

(a)

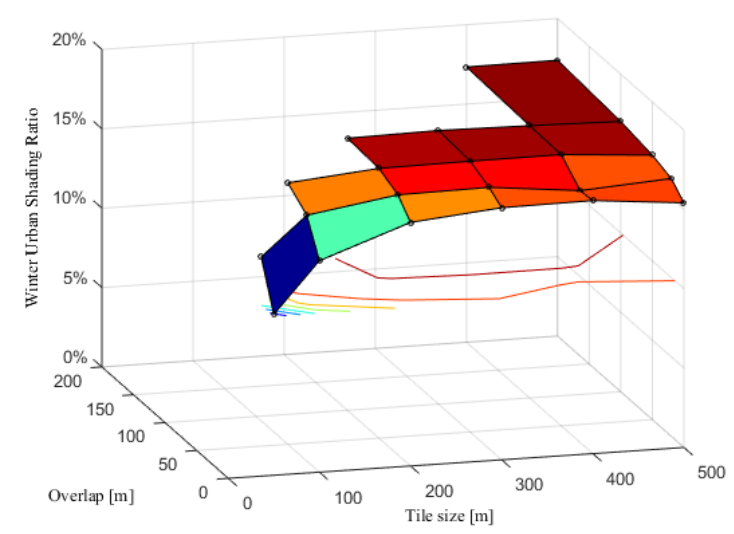

(c)

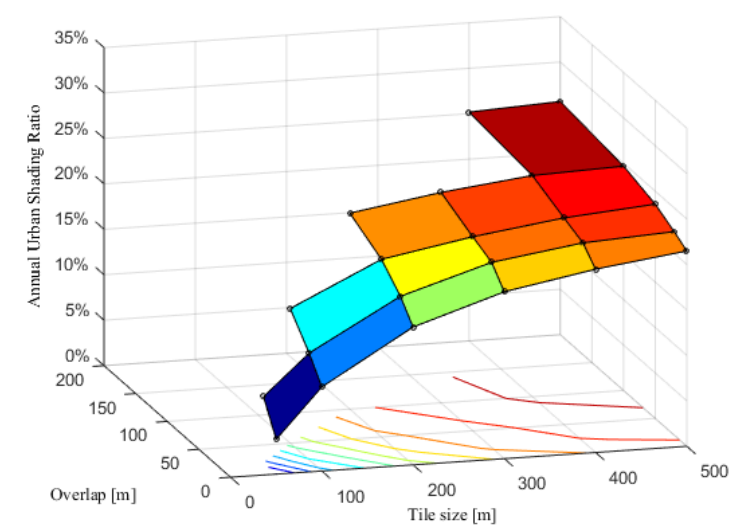

(b)

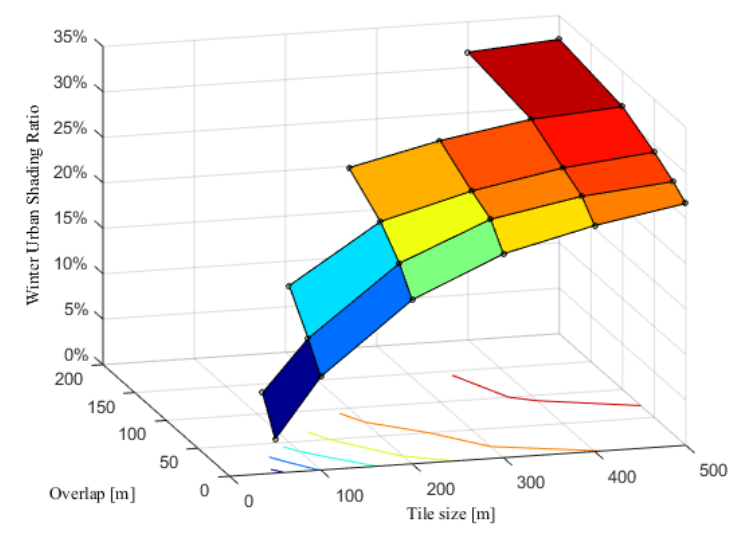

(d) 


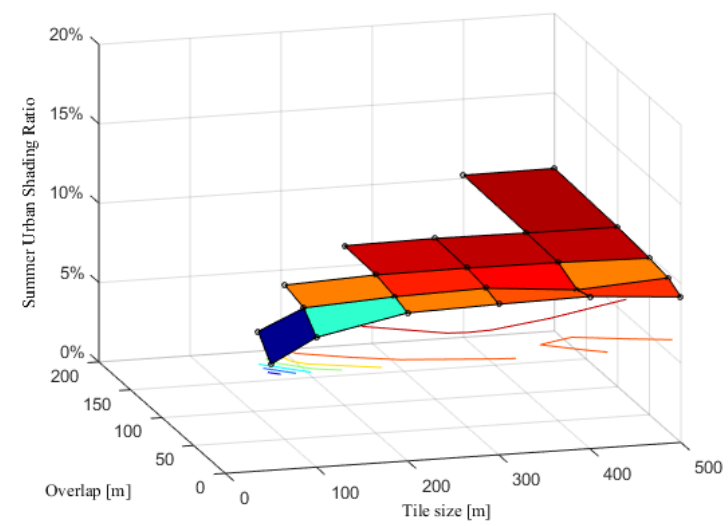

(e)

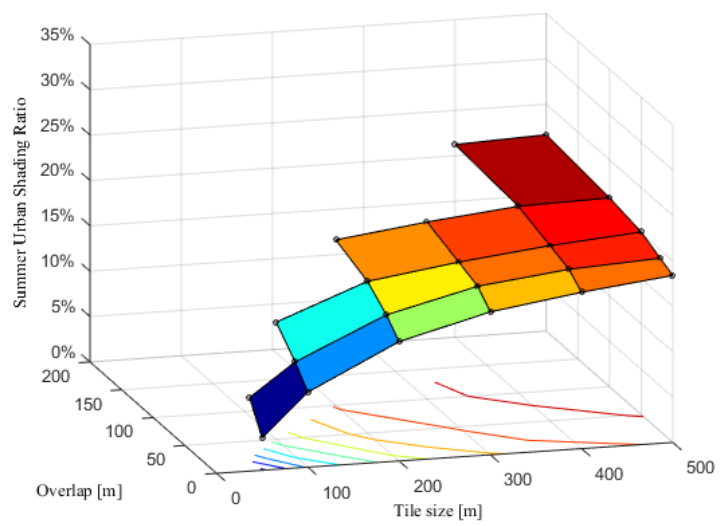

(f)

Figure 9: Urban Shading Ratios on roofs as a function of the used tiling strategy. (a) is the annual USR in Ludwigsburg, (b) is the annual USR in Manhattan, (c) is the winter USR in Ludwigsburg, (d) is the winter USR in Manhattan, (e) is the summer USR in Ludwigsburg and (f) is the summer USR in Manhattan

Higher tile sizes have higher Urban Shading Ratios. This means that when the number of considered buildings increases, the impact of obstructions is generally higher than the impact of reflections. A second clear outcome of Figure 9 is the relative difference of USR between both case studies: the high-density urban area of Manhattan has an USR two times higher than the middle-density area of Ludwigsburg.

For the most accurate tested tiling strategy $\{$ tile size $=500 \mathrm{~m}$, overlap $=200 \mathrm{~m}$ \}, the annual USR reaches $12.8 \%$ and $25.7 \%$ for the case studies of Ludwigsburg and Manhattan respectively. Focusing on the winter period, this USR goes up to $17.4 \%$, respectively $32.4 \%$. Conversely, the worst tiling strategies \{tile size $=50 \mathrm{~m}$, no overlap $\}$ present USR for both case studies between 5 and $10 \%$.

A further important insight is related to the form of these 3D surfaces: they are "flatter" in the case of Ludwigsburg than for Manhattan. Indeed, the Ludwigsburg's 3D surfaces are almost tangential to the horizontal plane defined by the highest point $\{$ tile size $=500 \mathrm{~m}$, overlap $=200 \mathrm{~m}\}$. Its maximum may even be reached with a deviation lower than $1 \%$ by the tiling strategy $\{$ tile size $=200 \mathrm{~m}$, overlap $=100 \mathrm{~m}$ \}. In the case of Manhattan, the 3D surface has not reached yet a tangential point. By extrapolating the 3D surface toward higher sizes and overlap parameters, the annual USR higher limit might reach $29 \% \pm 2 \%$.

\subsection{Tiling strategy comparison for facade irradiance}

In this section, only the solar radiations on the building facade surfaces are considered, as it is generally the case for building heating or cooling demand simulations, daylighting analyses or studies of building integrated photovoltaics, which may have a relevant role in urban environments (Brito et al., 2017). The USR presented in Figure 10 is the average of the USR on all facades, weighted by their area. This averaging method gives more importance to the bigger facades and bigger buildings. As illustrated by Figures 9 and 10, the USR of facades are much higher (factor 2 to 3 ) than for roofs. This result is due to the bigger surrounding occlusions and therefore lower sky view factor of the facades. 


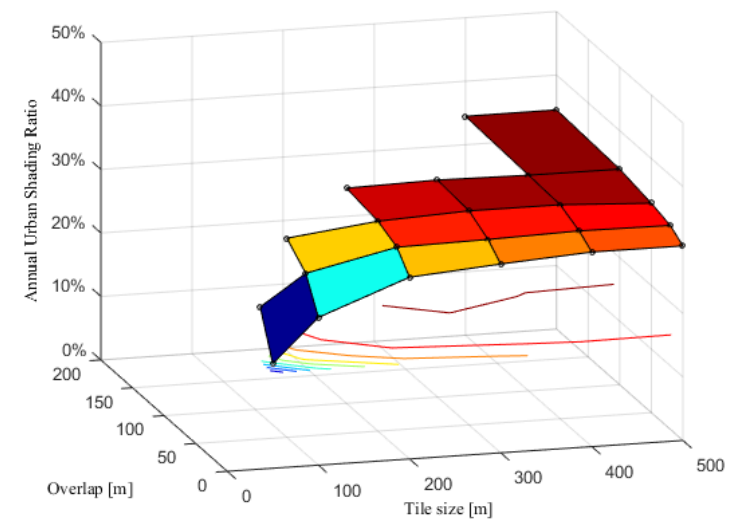

(a)

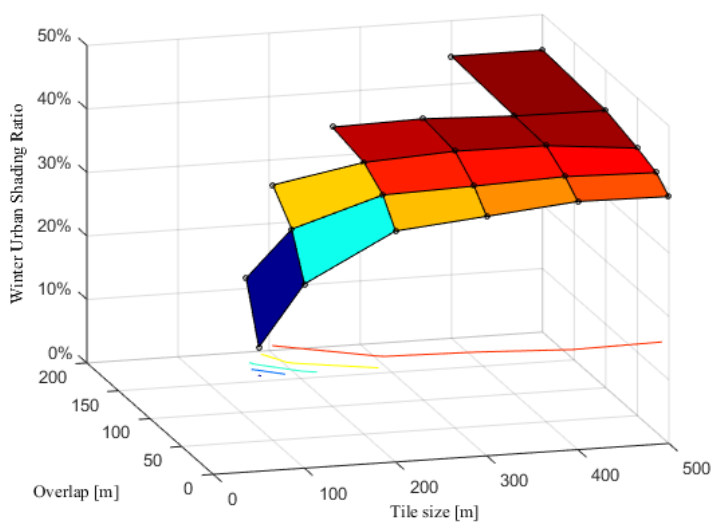

(c)

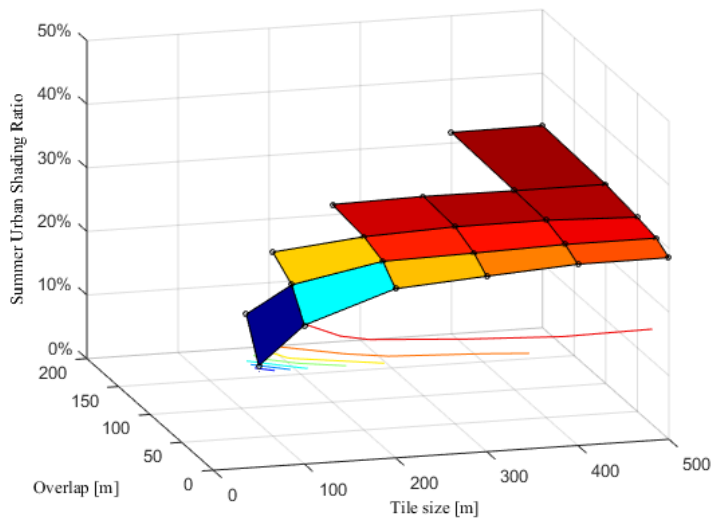

(e)

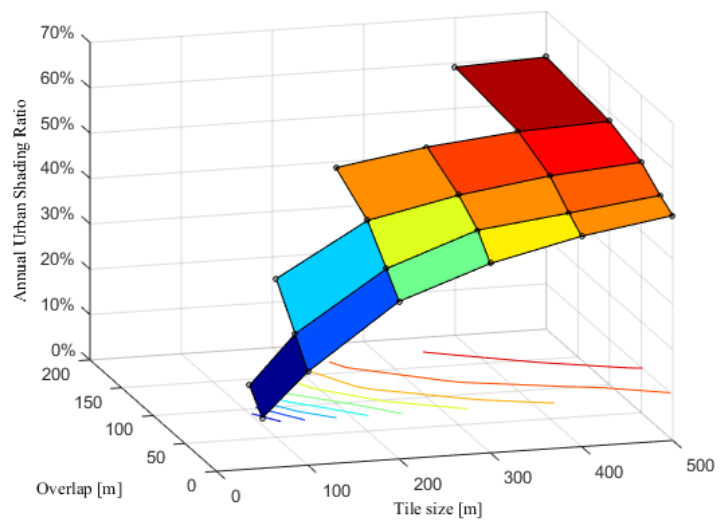

(b)

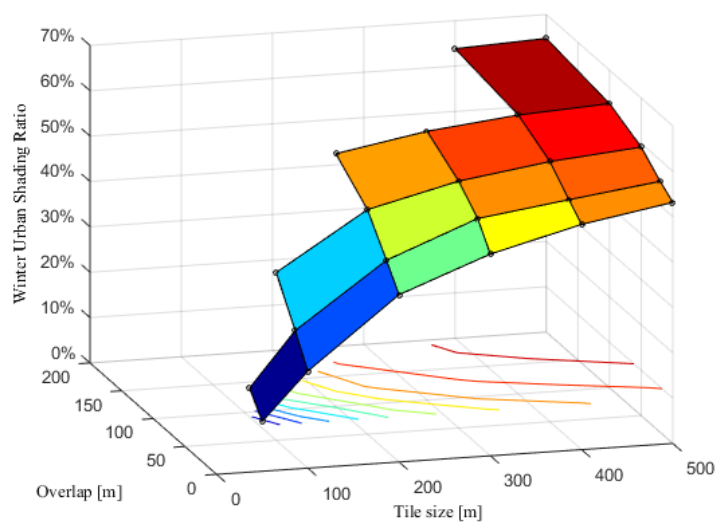

(d)

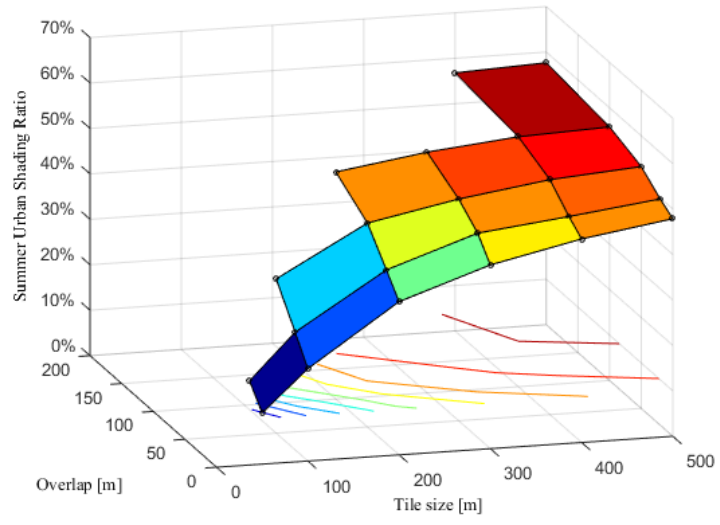

(f)

Figure 10: Urban Shading Ratios on facades as a function of the used tiling strategy. (a) is the annual USR in Ludwigsburg, (b) is the annual USR in Manhattan, (c) is the winter USR in Ludwigsburg, (d) is the winter USR in Manhattan, (e) is the summer USR in Ludwigsburg and (f) is the summer USR in Manhattan

Many similarities exist between roofs and facades USR: the high-density urban area of Manhattan have USR quasi twice higher than the middle-density area of Ludwigsburg. Moreover, the 3D surfaces in the case of Ludwigsburg are flatter than in Manhattan. In the former case, the 3D surfaces are almost tangential to the horizontal plane defined by the highest point $\{$ size $=500 \mathrm{~m}$, overlap $=200 \mathrm{~m}\}$, with an annual USR of $34.5 \%$. This result is approached with a deviation lower than $1 \%$ for the tiling strategy \{size $=300 \mathrm{~m}$, overlap $=100 \mathrm{~m}\}$, and of $2 \%$ for the tiling strategies $\{$ size $=200 \mathrm{~m}$, overlap $=100 \mathrm{~m}\}$ and $\{$ size $=300 \mathrm{~m}$, overlap $=50 \mathrm{~m}\}$. Winter USR and Summer USR reaches respectively $44.4 \%$ and $31.8 \%$. 
In the case of Manhattan, a highest annual USR of $60.0 \%$ is obtained for the tiling strategy $\{$ size $=500 \mathrm{~m}$, overlap $=200 \mathrm{~m}\}$. However, the $3 \mathrm{D}$ surface is not yet tangent to the horizontal plane at this point. By extrapolating the surface toward higher size and overlap parameters, the annual USR higher limit would reach $62 \% \pm 1 \%$. Winter USR and Summer USR reaches respectively $57.6 \%$ and $64.7 \%$.

As an outcome of this study for both roofs and facades, the tiling strategy size $=300 \mathrm{~m}$, overlap $=100 \mathrm{~m}$ ) can be considered as an accurate solar radiation calculation method for the case study Ludwigsburg, with a relative uncertainty below $1 \%$. It represents a good compromise between accuracy and computational performance. For the case study Manhattan, any tiling strategy below $\{$ size $=500 \mathrm{~m}$, overlap $=200 \mathrm{~m}$ \} reduces the USR significantly (by $5 \%$ or more), and therefore would be considered as inaccurate in comparison. Consequently, the solar radiations on roofs and facades should be calculated at least with these "best tiling strategies", which are used in the next section.

\section{Solar analyses in medium and high-density urban areas}

\subsection{Solar potential "Identity Cards”}

In order to assess the energy solar potential of a city district, it is often useful to quantify the total building surface area throughout the district that exceeds different solar energy thresholds. Facades of different orientations, flat roofs, and pitched roofs are distinguished for both case studies. As previously mentioned, only flat roofs are considered in Manhattan whereas an important part (60\%) of the buildings of Ludwigsburg are represented with pitched roofs (see Figure 11). The cumulative solar radiation distribution represented in Figure 12 and Figure 13 show an example of solar potential "identity cards" of the case studies.

In the case study Ludwigsburg, the total building external surface area is two square kilometers. Two thirds of it are facade surfaces, $20 \%$ are pitched roofs and the remaining $13 \%$ are flat roofs. Half of this surface area does not receive more than $600 \mathrm{kWh} / \mathrm{m}^{2} . \mathrm{yr}$, mainly due to shading and unfavorable orientation of the facades. Regarding the surfaces receiving more than $800 \mathrm{kWh} / \mathrm{m}^{2}$.yr solar radiation: only $15 \%$ of them are facades (representing $7 \%$ of all facades), $50 \%$ are pitched roofs and $34 \%$ are flat roofs. This trend is emphasized if one considers the surface areas receiving a minimum of 1000 $\mathrm{kWh} / \mathrm{m}^{2} . \mathrm{yr}$, the typical threshold of photovoltaic installation profitability: $57 \%$ are pitched roofs, $43 \%$ are flat roofs, and no facades are present. The solar radiation received by flat roofs is limited by the global horizontal radiation (approximately $1150 \mathrm{kWh} / \mathrm{m}^{2}$.yr in Ludwigsburg). However, mounting solar systems on flat roofs with a favorable tilt and orientation ( $35^{\circ}$ South) enable to collect up to $1350 \mathrm{kWh} / \mathrm{m}^{2} . \mathrm{yr}$. 


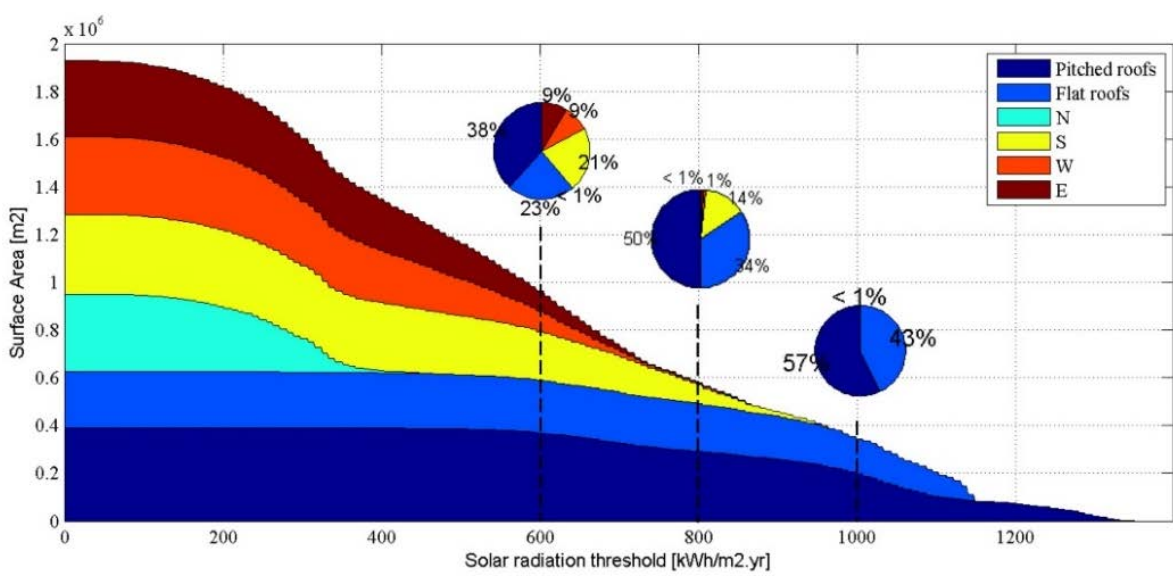

Figure 12: Cumulative solar radiation distribution in Ludwigsburg.

The Manhattan case study includes a total of almost $25 \mathrm{~km}^{2}$ building surface area, of which $85 \%$ are facades. However, the latter represents only $39 \%$ and $20 \%$ of the surface area receiving more than 600 , respectively $800 \mathrm{kWh} / \mathrm{m}^{2} . \mathrm{yr}$, and none of them receive more than $1000 \mathrm{kWh} / \mathrm{m}^{2} . \mathrm{yr}$. In comparison, $54 \%$ of all roof area receives more than $1000 \mathrm{kWh} / \mathrm{m}^{2} . \mathrm{yr}$ in Manhattan. While comparing both cumulative solar radiation distributions, the curve of Ludwigsburg is almost linear between the radiation thresholds 200 and $1200 \mathrm{kWh} / \mathrm{m}^{2} . \mathrm{yr}$, whereas the curve of Manhattan is much more convex.

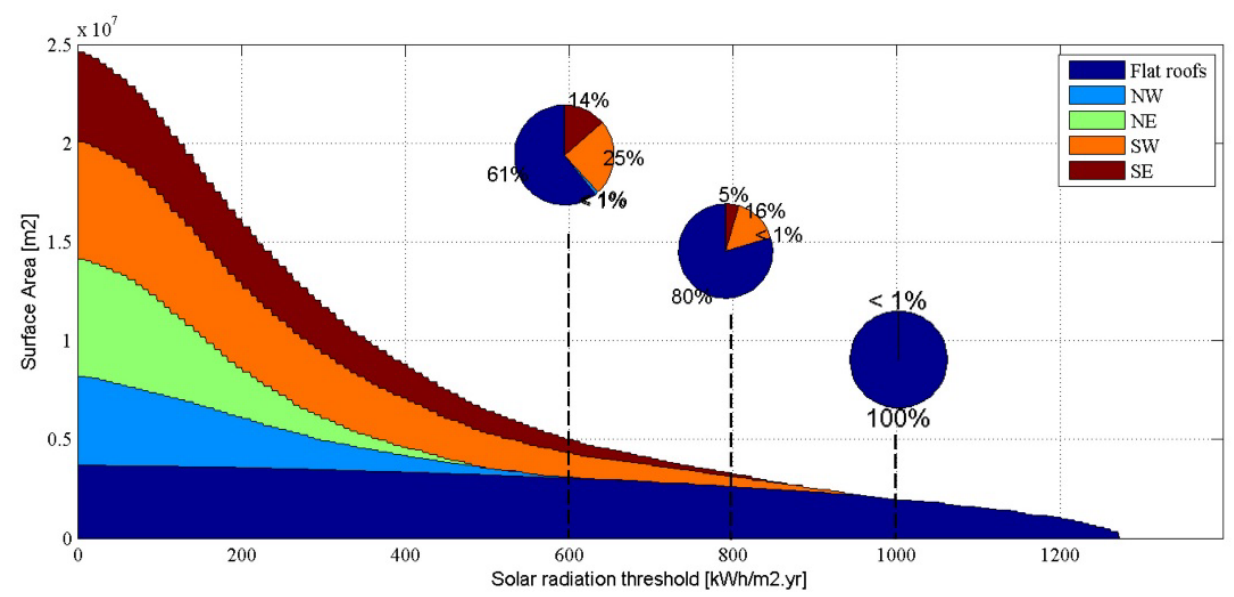

Figure 13: Cumulative solar radiation distribution in Manhattan.

In conclusion, although facades represent most of building surface areas (two thirds in Ludwigsburg and 85\% in Manhattan), roofs have a greater potential for an economic exploitation of available solar energy than facades do. However, the use of facades should not be disregarded for photovoltaic generation due to the large areas concerned. The solar radiation on flat roofs may be optimally used by mounting tilted solar panels with a favorable orientation (between 25 and $35^{\circ}$ south in latitudes like in Manhattan and Ludwigsburg). To be also noted, each building surface has only one incoming solar radiation value, computed by the Radiosity algorithm on its center. Therefore, a facade may have a (upper) part which receives more than the specified solar radiation threshold, but this was not considered in the graphs above.

\subsection{Solar irradiance per facade orientation}

The solar potential of a facade with consideration of the urban shading depends obviously on the surface orientation and the period of the year. In this section, the solar irradiances received on different facade orientations are investigated in more detail for both case studies. A "no-shading" reference case, which corresponds to the unobstructed scenario with the maximum solar potential, is compared with the "best tiling strategies” found out in Section 4. Facades are regrouped by orientations, with a $\pm 22.5^{\circ}$ azimuth 
tolerance (i.e. "South" corresponds to facade azimuth $\left.\epsilon\left[157.5^{\circ}, 202.5^{\circ}\right]\right)$. Figure 15 and Figure 18 also include the USR of flat roofs, which are always lower than those of the facades.

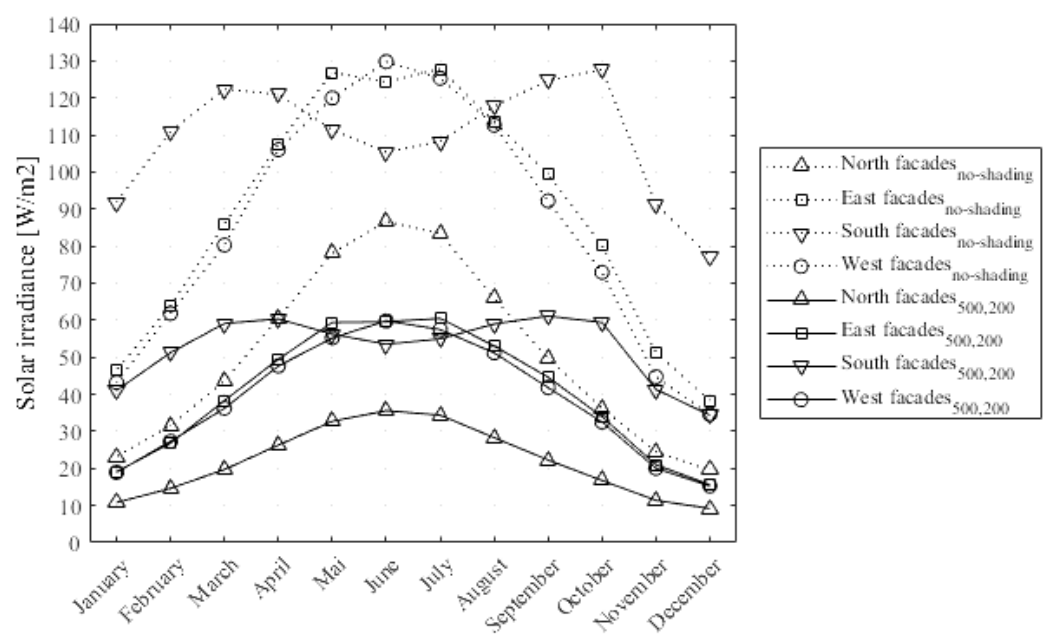

Figure 14: Monthly irradiances on facades in Manhattan, with and without shading consideration

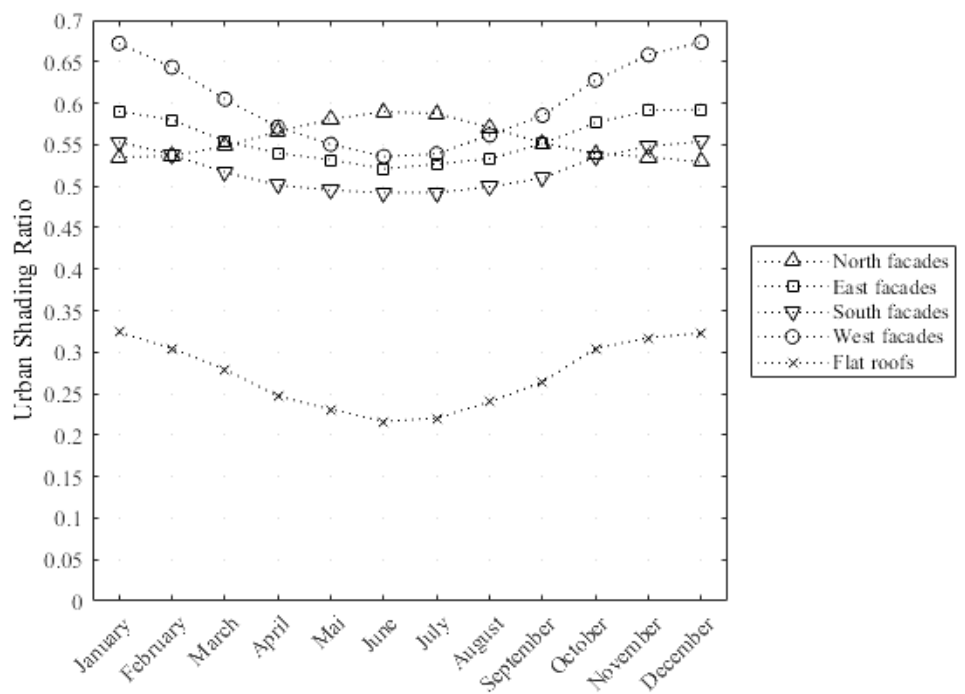

Figure 15: Monthly Urban Shading Ratio on roofs and facades in Manhattan

With or without urban shading consideration, the monthly irradiances on the North, East and West facades show a typical bell form which culminates in June, whereas the solar irradiance on the South facade shows two maxima in Spring and Autumn. The monthly USR of the different facades remains relatively stable over the whole year, varying between 0.5 and 0.7 , depending on the orientations and month of the year. The West facades have an USR between 0.1 and 0.2 higher than the other facades (particularly over East facades) in winter, which is due to the regular street layout oriented SSW / NNE, generating considerable shading on the WNW facade when the winter sun is low.

The USR yearly variation of the North facades with higher values in summer than in winter is the opposite to that of the other facades. The sun trajectories in front of the different facade orientations explain part of this outcome (see Figure 16): contrary to other facade orientations, north facades receive direct radiations only in summer and middle seasons. However, in a dense urban area this direct beam is often shaded by surrounding buildings since the morning and evening sun position is relatively low. This tends to increase the USR in the summer season. 

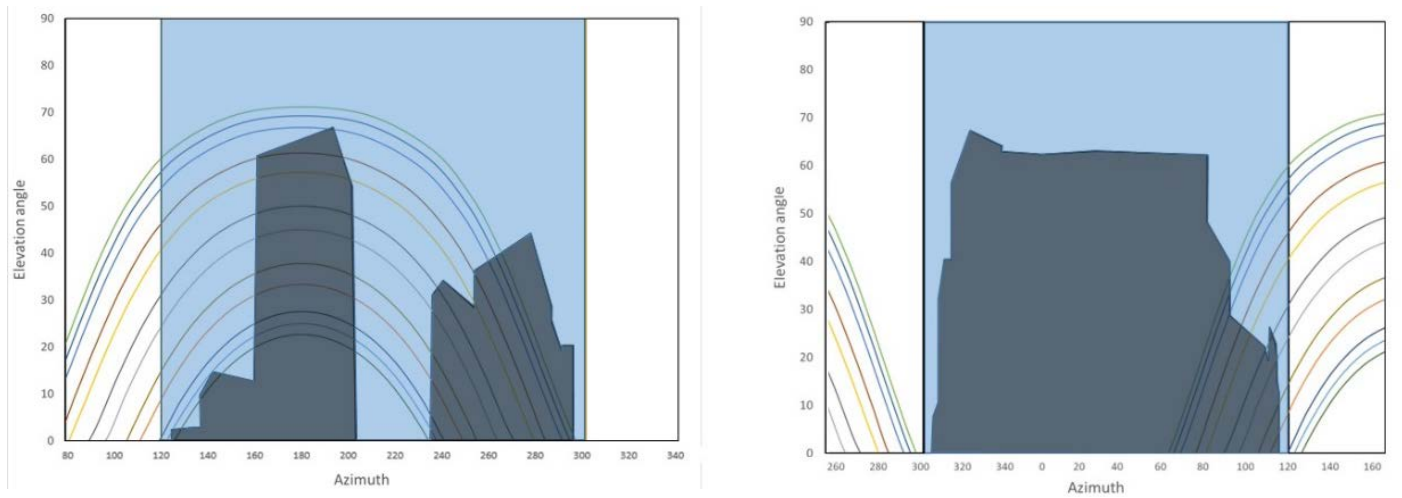

Figure 16: Example of neighboring building obstructions seen from the middle point of a SSW facade (left) and a NNE facade (right) of a building in Manhattan.

The general trends are similar in the case study of Ludwigsburg, although the USR are significantly lower than in Manhattan (see Figure 18), as already calculated in the previous chapter. The USR yearly variation has a wider amplitude from 0.25 to 0.51 as compared to Manhattan. The street layouts, regular in the case of Manhattan and without real pattern in the case of Ludwigsburg, explain this difference. For the South facades, the solar irradiance maxima are less pronounced and closer to each other than for Manhattan, due to the difference of latitude between these two locations.

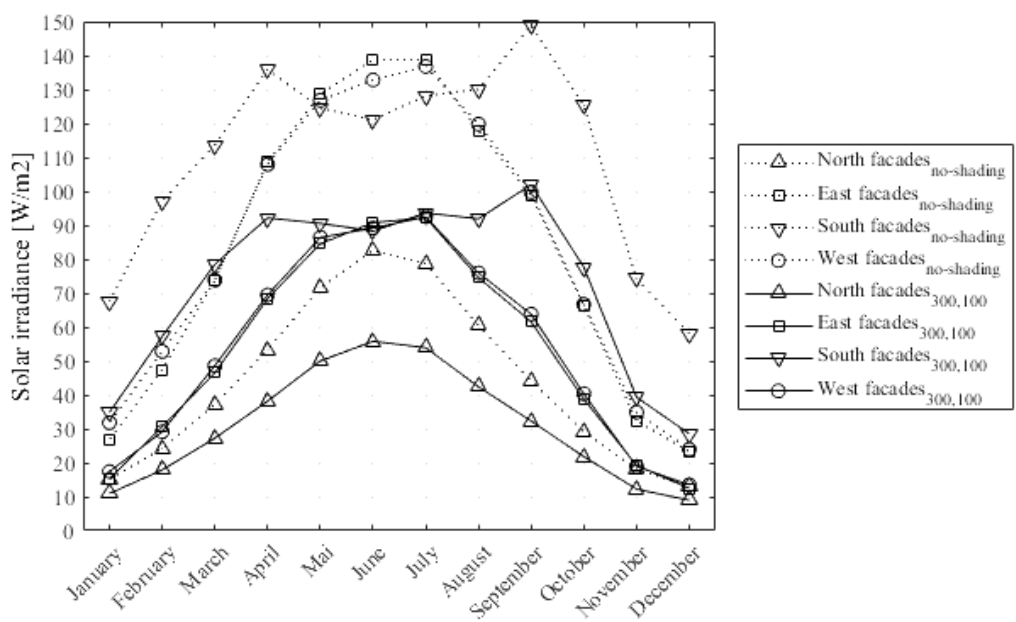

Figure 17: Monthly irradiances on facades in Ludwigsburg, with and without shading consideration

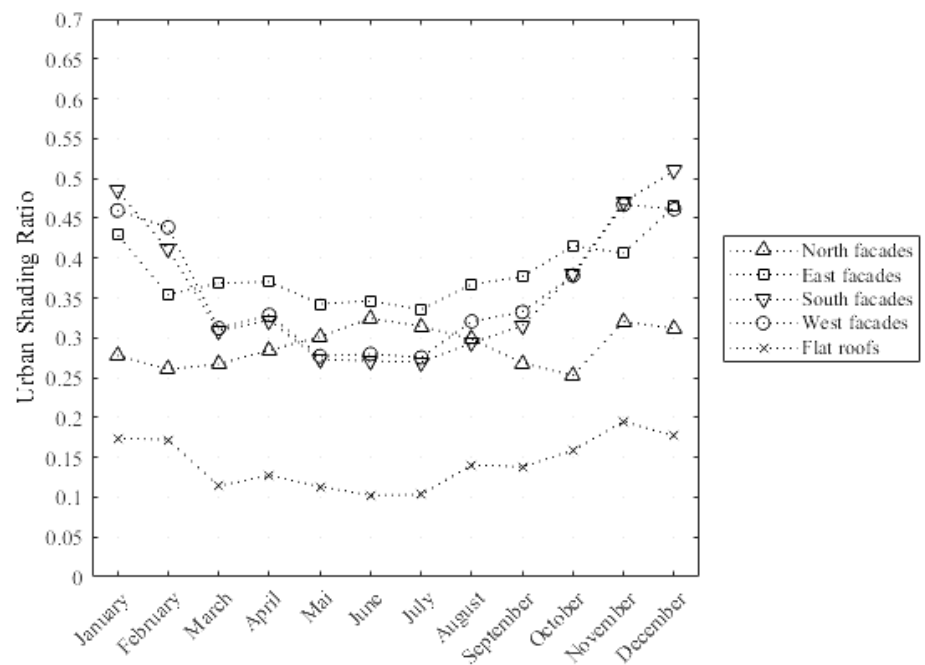

Figure 18: Monthly Urban Shading Ratio on roofs and facades in Ludwigsburg 
489 In this study, different methods of solar radiation computation in urban areas have been compared. Two representative urban case studies of different densities in New York and Ludwigsburg (Germany) have been used for the evaluation, employing 3D city models based on the CityGML format for a full and realistic urban environment analysis. Since the number of surface interactions and radiation exchanges increase exponentially with the scale of districts, innovative computational strategies for solar irradiance modeling considering shading and inter-reflections have been introduced, partitioning the two case studies in square tiles of different sizes and overlaps to evaluate the computing performance.

The main contribution of this study is the accurate quantification at urban scale of the considerable impact of urban shading and multiple reflections on the solar radiation incoming on the building surfaces. They reduce annual solar irradiance by up to $60 \%$ for facades and $25 \%$ for roofs in high-density urban areas such as Manhattan. Square tile sizes of more than 300 meters length for medium density districts such as Ludwigsburg are sufficient to calculate with $1 \%$ uncertainty the solar radiation including shading and inter-reflections. In high-density districts like Manhattan, a tile size length of 500 meters is a minimum requirement.

This work has also justified quantitatively that the traditional method applied in building performance simulations, which considers only the direct-neighbor buildings, is far from enough to calculate reliably the solar radiation reaching a given building. Therefore, assessing this phenomenon accurately is of paramount importance for any reliable energy analysis in an urban context, including solar potential analysis, daylighting analysis as well as heating and cooling load calculations.

A promising improvement to the use of fixed square tiles in this study would consist in splitting the urban scene in tiles of variable sizes and forms, according to the main street axis and the local density. Studying more case studies of different densities is necessary to continue the present work, possibly generated randomly with a tool like Random3DCity (Biljecki et al., 2016). The Stuttgart University of Applied Sciences is currently developing an automated method based on OpenStreetMap data for this purpose.

Finally, an intelligent surface meshing would be an important step forward for this work. Presently, each building surface defined in the 3D city models has only one incoming solar radiation value, computed by the Radiosity algorithm on its center. This may be problematic, in particular for high facades whose basis and upper part have very different solar potentials, related to different sky view factors. On the other hand, meshing systematically all building surfaces sky-rockets the number of polygons computed by the Radiosity algorithm and aggravates the related computational issues identified in this study. Therefore, an intelligent and adaptive meshing method compatible with urban-scale requirements is essential. One approach would be to vary the mesh size depending on the sky view factor at the center of each building surface, or on the local built density. Another possibility would consist in calculating the solar radiation on the edges of each polygon and interpolate in a post-processing phase the solar radiation over the entire facades and roofs.

Assessing and understanding the solar potential of cities is essential in the context of the urban energy transition. Every innovative computational method which improves the accuracy and efficacy of the solar radiation calculation at urban scale, is a step forward for the research community as well as the environment. 


\section{References}

A.l. Martins, T., Adolphe, L., E.g. Bastos, L., 2014. From solar constraints to urban design opportunities: Optimization of built form typologies in a Brazilian tropical city. Energy Build. 76, 43-56. doi:10.1016/j.enbuild.2014.02.056

Behar, O., Khellaf, A., Mohammedi, K., 2015. Comparison of solar radiation models and their validation under Algerian climate - The case of direct irradiance. Energy Convers. Manag. 98, 236-251. doi:10.1016/j.enconman.2015.03.067

Bernabé, A., Musy, M., Andrieu, H., Calmet, I., 2015. Radiative properties of the urban fabric derived from surface form analysis: A simplified solar balance model. Sol. Energy 122, 156-168. doi:10.1016/j.solener.2015.08.031

Biljecki, F., Heuvelink, G.B.M., Ledoux, H., Stoter, J., 2015. Propagation of positional error in 3D GIS: estimation of the solar irradiation of building roofs. Int. J. Geogr. Inf. Sci. 8816, 1-26. doi:10.1080/13658816.2015.1073292

Biljecki, F., Ledoux, H., Stoter, J., 2016. Generation of multi-LOD 3D city models in CityGML with the procedural modelling engine Random3Dcity. ISPRS Ann. Photogramm. Remote Sens. Spat. Inf. Sci. IV-4/W1, 51-59. doi:10.5194/isprs-annals-IV-4-W1-51-2016

Brito, M.C., Freitas, S., Guimaraes, S., Catita, C., Redweik, P., 2017. The importance of facades for the solar PV potential of a Mediterranean city using LiDAR data. Renew. Energy 111, 85-94. doi:10.1016/j.renene.2017.03.085

Catita, C., Redweik, P., Pereira, J., Brito, M.C., 2014. Extending solar potential analysis in buildings to vertical facades. Comput. Geosci. 66, 1-12. doi:10.1016/j.cageo.2014.01.002

Cellura, M., Di Gangi, A., Orioli, A., 2011. A photographic method to estimate the shading effect of obstructions. Sol. Energy 86, 886-902. doi:10.1016/j.solener.2011.12.018

CUNY, 2016. New York City Solar Map. http://www.cuny.edu/about/resources/sustainability/solaramerica/map.html [WWW Document].

Despotovic, M., Nedic, V., Despotovic, D., Cvetanovic, S., 2016. Evaluation of empirical models for predicting monthly mean horizontal diffuse solar radiation. Renew. Sustain. Energy Rev. 56, 246260. doi:10.1016/j.rser.2015.11.058

Despotovic, M., Nedic, V., Despotovic, D., Cvetanovic, S., 2015. Review and statistical analysis of different global solar radiation sunshine models. Renew. Sustain. Energy Rev. 52, 1869-1880. doi:10.1016/j.rser.2015.08.035

Eicker, U., Nouvel, R., Duminil, E., Coors, V., 2014. Assessing passive and active solar energy resources in cities using 3D city models. Energy Procedia 57, 896-905. doi:10.1016/j.egypro.2014.10.299

El Mghouchi, Y., El Bouardi, A., Sadouk, A., Fellak, I., Ajzoul, T., 2016. Comparison of three solar radiation models and their validation under all sky conditions - Case study: Tetuan city in northern of Morocco. Renew. Sustain. Energy Rev. 58, 1432-1444. doi:10.1016/j.rser.2015.12.354

Fath, K., Stengel, J., Sprenger, W., Wilson, H.R., Schultmann, F., Kuhn, T.E., 2015. A method for predicting the economic potential of (building-integrated) photovoltaics in urban areas based on hourly Radiance simulations. Sol. Energy 116, 357-370. doi:10.1016/j.solener.2015.03.023

Freitas, S., Catita, C., Redweik, P., Brito, M.C., 2015. Modelling solar potential in the urban environment: State-of-the-art review. Renew. Sustain. Energy Rev. 41, 915-931. doi:10.1016/j.rser.2014.08.060

Good, C.S., Lobaccaro, G., Hårklau, S., 2014. Optimization of Solar Energy Potential for Buildings in Urban Areas - A Norwegian Case Study. Energy Procedia 58, 166-171. doi:10.1016/j.egypro.2014.10.424

Gröger, G., Kolbe, T.H., Nagel, C., Häfele, K.-H. (Eds.), 2012. OGC City Geography Markup Language (CityGML) Encoding Standard, Version 2.0.0. Open Geospatial Consortium, OGC Doc.No.12-019. 
Gueymard, C.A., Ruiz-Arias, J.A., 2016. Extensive worldwide validation and climate sensitivity analysis of direct irradiance predictions from 1-min global irradiance. Sol. Energy 128, 1-30.

doi:10.1016/j.solener.2015.10.010

Han, Y., Taylor, J.E., Pisello, A.L., 2015. Exploring mutual shading and mutual reflection inter-building effects on building energy performance. Appl. Energy. doi:10.1016/j.apenergy.2015.10.170

Hay, J.E., 1979. Calculation of monthly mean solar radiation for horizontal and inclined surfaces. Sol. Energy 23, 301-307. doi:10.1016/0038-092X(79)90123-3

Hong, T., Lee, M., Koo, C., Jeong, K., Kim, J., 2017. Development of a method for estimating the rooftop solar photovoltaic (PV) potential by analyzing the available rooftop area using Hillshade analysis. Appl. Energy 194, 320-332. doi:10.1016/j.apenergy.2016.07.001

IEA, 2002. Potential for building integrated photovoltaics. Rep. IEA - PVPS T7-4 2002.

Ineichen, P., 2016. Validation of models that estimate the clear sky global and beam solar irradiance. Sol. Energy 132, 332-344. doi:10.1016/j.solener.2016.03.017

Izquierdo, S., Rodrigues, M., Fueyo, N., 2008. A method for estimating the geographical distribution of the available roof surface area for large-scale photovoltaic energy-potential evaluations. Sol. Energy 82, 929-939. doi:10.1016/j.solener.2008.03.007

Jaugsch, F., Lowner, M.-O., 2016. Estimation of Solar Energy on Vertical 3D Building Walls on City Quarter Scale. ISPRS - Int. Arch. Photogramm. Remote Sens. Spat. Inf. Sci. XLII-2/W2, 135-143. doi:10.5194/isprs-archives-XLII-2-W2-135-2016

Karteris, M., Theodoridou, I., Mallinis, G., Papadopoulos, A.M., 2014. Facade photovoltaic systems on multifamily buildings: An urban scale evaluation analysis using geographical information systems. Renew. Sustain. Energy Rev. 39, 912-933. doi:10.1016/j.rser.2014.07.063

Klucher, T.M., 1979. Evaluation of models to predict insolation on tilted surfaces. Sol. Energy 23, $111-$ 114. doi:10.1016/0038-092X(79)90110-5

Kolbe, T., Burger, B., Cantzler, B., 2015. City GML goes to Broadway. Photogramm. Weeks 343-355.

Koronakis, P.S., 1986. On the choice of the angle of tilt for south facing solar collectors in the Athens basin area. Sol. Energy 36, 217-225. doi:10.1016/0038-092X(86)90137-4

Košir, M., Capeluto, I.G., Krainer, A., Kristl, Ž., 2014. Solar potential in existing urban layouts-Critical overview of the existing building stock in Slovenian context. Energy Policy 69, 443-456. doi:10.1016/j.enpol.2014.01.045

Kurdgelashvili, L., Li, J., Shih, C.-H., Attia, B., 2016. Estimating technical potential for rooftop photovoltaics in California, Arizona and New Jersey. Renew. Energy 95, 286-302. doi:10.1016/j.renene.2016.03.105

Lee, K.S., Lee, J.W., Lee, J.S., 2016. Feasibility study on the relation between housing density and solar accessibility and potential uses. Renew. Energy 85, 749-758. doi:10.1016/j.renene.2015.06.070

Li, D., Liu, G., Liao, S., 2015. Solar potential in urban residential buildings. Sol. Energy 111, 225-235. doi:10.1016/j.solener.2014.10.045

Liu, B.Y.H., Jordan, R.C., 1960. The interrelationship and characteristic distribution of direct, diffuse and total solar radiation. Sol. Energy 4, 1-19. doi:10.1016/0038-092X(60)90062-1

Lobaccaro, G., Frontini, F., 2014. Solar energy in urban environment: How urban densification affects existing buildings. Energy Procedia 48, 1559-1569. doi:10.1016/j.egypro.2014.02.176

LUBW, 2015. Roof surface potential analyse of the Landesanstalt für Umwelt, Messungen und Naturschutz Baden-Württemberg (LUBW). http://www.energieatlas-bw.de/sonne/dachflachen.

Montes-Amoros, V., 2015. When buildings attack their neighbors: Strategies for protecting against "death rays.” CTBUH J. 20-25.

Nouvel, R., Brassel, K.-H., Bruse, M., Duminil, E., Coors, V., Eicker, U., Robinson, D., 2015 a. 
SIMSTADT , a New Worflow-driven Urban Energy Simulation Platform for CityGML City Models. CISBAT 2015 - Lausanne, Switz. 889-894.

Nouvel, R., Mastrucci, A., Leopold, U., Baume, O., Coors, V., Eicker, U., 2015b. Combining GIS-based statistical and engineering urban heat consumption models: Towards a new framework for multiscale policy support. Energy Build. 107, 204-212. doi:10.1016/j.enbuild.2015.08.021

Nouvel, R., Zirak, M., Coors, V., Eicker, U., 2017. The influence of data quality on urban heating demand modeling using 3D city models. Comput. Environ. Urban Syst. 64, 68-80. doi:10.1016/j.compenvurbsys.2016.12.005

Perez, R., Ineichen, P., Seals, R., Michalsky, J., Stewart, R., 1990. Modeling daylight availability and irradiance components from direct and global irradiance. Sol. Energy 44, 271-289. doi:10.1016/0038-092X(90)90055-H

Redweik, P., Catita, C., Brito, M., 2013. Solar energy potential on roofs and facades in an urban landscape. Sol. Energy 97, 332-341. doi:10.1016/j.solener.2013.08.036

Reindl, D.T., Beckman, W.A., Duffie, J.A., 1990. Diffuse fraction correlations. Sol. Energy 45, 1-7. doi:10.1016/0038-092X(90)90060-P

Reinhart, C.F., Dogan, T., Jakubiec, J.A., Rakha, T., Sang, A., 2013. Umi - an Urban Simulation Environment for Building Energy Use, Daylighting and Walkability. Proc. BS2013 13th Conf. Int. Build. Perform. Simul. Assoc. 476-483.

Robinson, D., Haldi, F., Kämpf, J.H., Leroux, P., Perez, D., Rasheed, a, Wilke, U., 2009. CITYSIM: Comprehensive Micro-Simulation Of Resource Flows For Sustainable Urban Planning. Int. IBPSA Conf. 1083-1090.

Robinson, D., Stone, A., 2005. A simplified radiosity algorithm for general urban radiation exchange. Build. Serv. Eng. Res. Technol. 26, 271-284. doi:10.1191/0143624405bt133oa

Romero Rodríguez, L., Duminil, E., Sánchez Ramos, J., Eicker, U., 2017. Assessment of the photovoltaic potential at urban level based on 3D city models: A case study and new methodological approach. Sol. Energy 146, 264-275. doi:10.1016/j.solener.2017.02.043

Sarralde, J.J., Quinn, D.J., Wiesmann, D., Steemers, K., 2015. Solar energy and urban morphology: Scenarios for increasing the renewable energy potential of neighbourhoods in London. Renew. Energy 73, 10-17. doi:10.1016/j.renene.2014.06.028

Schallenberg-Rodríguez, J., 2013. Photovoltaic techno-economical potential on roofs in regions and islands: The case of the Canary Islands. Methodological review and methodology proposal. Renew. Sustain. Energy Rev. 20, 219-239. doi:10.1016/j.rser.2012.11.078

Shukla, K.N., Rangnekar, S., Sudhakar, K., 2015. Comparative study of isotropic and anisotropic sky models to estimate solar radiation incident on tilted surface: A case study for Bhopal, India. Energy Reports 1, 96-103. doi:10.1016/j.egyr.2015.03.003

SimStadt, 2016. http://www.simstadt.eu/en/index.html.

Takebayashi, H., Ishii, E., Moriyama, M., Sakaki, A., Nakajima, S., Ueda, H., 2015. Study to examine the potential for solar energy utilization based on the relationship between urban morphology and solar radiation gain on building rooftops and wall surfaces. Sol. Energy 119, 362-369. doi:10.1016/j.solener.2015.05.039

Tregenza, P.R., 1987. Subdivision of the sky hemisphere for luminance measurements. Light. Res. Technol. 19, 13-14. doi:10.1177/096032718701900103

Vermeulen, T., Knopf-Lenoir, C., Villon, P., Beckers, B., 2015. Urban layout optimization framework to maximize direct solar irradiation. Comput. Environ. Urban Syst. 51, 1-12. doi:10.1016/j.compenvurbsys.2015.01.001

Yang, X., Li, Y., 2015. The impact of building density and building height heterogeneity on average urban albedo and street surface temperature. Build. Environ. 90, 146-156.

doi:10.1016/j.buildenv.2015.03.037 
Zomer, C., Nobre, A., Reindl, T., Ruther, R., 2016. Shading analysis for rooftop BIPV embedded in a high-density environment: A case study in Singapore. Energy Build. 121, 159-164. doi:10.1016/j.enbuild.2016.04.010 